\title{
AVALIAÇÃO DO USO E OCUPAÇÃO DAS ÁREAS DE PRESERVAÇÃO PERMANENTE NOS ANOS DE 2008 E 2013 NA ZONA URBANA DE HUMAITÁ, AMAZONAS
}

\author{
Tereza Cristina Efigenia MACHADO ${ }^{1}$ \\ Milton César Costa CAMPOS ${ }^{2}$ \\ Caio Henrique Patrício PAGANI ${ }^{1}$ \\ Jose Mauricio CUNHA ${ }^{3}$ \\ Marcelo Dayron Rodrigues SOARES ${ }^{3}$
}

\begin{abstract}
${ }^{1}$ Engenharia Ambiental, Universidade Federal do Amazonas - UFAM - Campus de Humaitá, e-mail: mcesarsolos@gmail.com.

${ }^{2}$ Engenheiro Agrônomo, Professor Dr. Adjunto IV, Bolsista de Produtividade do CNPq - Universidade Federal do Amazonas - UFAM - Campus de Humaitá, e-mail: mcesarsolos@ gmail.com.

${ }^{2}$ Bacharel em Física, Professor Doutorando do Programa de Pós Graduação em Física Ambiental Adjunto I Universidade Federal do Amazonas - UFAM - Campus de Humaitá, e-mail: maujmc@gmail.com.

${ }^{3}$ Engenheiro Ambiental, Professor Doutorando do Programa de Pós Graduação em Engenharia Agrícola - Universidade Federal do Amazonas - UFAM - Campus de Humaitá, e-mail: marcelo.dayron@ gmail.com.
\end{abstract}

Recebido em: 28/06/2016 - Aprovado em: 30/11/2017 - Disponibilizado em: 30/12/2017

\begin{abstract}
RESUMO:
As Áreas de Preservação Permanente (APPs) foram criadas para proteger o ambiente natural e restringindo qualquer alteração de uso do solo. O objetivo deste trabalho foi avaliar o uso e cobertura das áreas de preservação permanente nos anos de 2008 e 2013 na zona urbana de Humaitá, Amazonas. O presente trabalho, utilizou o software ArcGIS 10.1 para delimitar as nascentes e as margens de cada igarapé foi realizado a classificação de uso e cobertura de solo através das imagens de alta resolução do Google Earth. Com o processamento dos dados foi possível delimitar as áreas de preservação permanente ao longo dos cursos d'água, as APPs totalizam com 29,23 hectares. Houve evolução no processo de ocupação desordenada e desmatamento das áreas de APPs para os anos de 2008 e 2013 . A área de Preservação 1 (APP-1) e Área de Preservação Permanente 3 (APP-3) apresentaram um aumento da área desmatada e diminuição da área verde, já a Área de Preservação Permanente 2 (APP-2) apresentou diminuição da área desmatada e aumento da área verde. E a utilização de mapas permitiu analisar espacialmente o processo de redução das áreas verdes, decorrentes das alterações no uso e ocupação do solo pelo qual passou a zona urbana do município de Humaitá, AM.

Palavras Chave: Áreas de preservação permanente. Ocupação desordenada. Geotecnologias. Amazônia.
\end{abstract}

\section{EVALUATION OF THE OCCUPATION AND USE OF PERMANENT PRESERVATION AREAS IN 2008 AND 2013 IN THE URBAN AREA OF HUMAITA, AMAZONAS}

\footnotetext{
ABSTRACT:

The Permanent Preservation Areas (PPAs) are designed to protect the natural environment and restricting any land use change. The objective of this study was to evaluate the use and occupation of permanent preservation areas in 2008 and 2013 in the urban area of Humaita, Amazonas state. This work used the ArcGIS 10.1 software to define the sources and margins of each stream, and performing the use of classification and ground cover through high-resolution images from Google Earth. With the data processing was possible to delimit the permanent preservation areas along the waterways, the PPAs amounted to 29.23 hectares. There was an increase in disorderly process of occupation and deforestation of PPAs areas for the years 2008 and 2013. The areas of permanent preservation 1 (PPA-1) and areas of permanent preservation 3 (PPA-3) showed an increase in deforested area and decreased green area, since the areas of permanent 
preservation 2 (PPA-2) exhibited reduced deforested area and increase the green area. And the use of maps allowed spatially analyze the process of reduction of green areas, resulting from changes in the use and occupation of land has gone through the urban area of the municipality of Humaita, Amazonas state.

Key words: Permanent preservation areas. Disorderly occupation. Geotechnology. Amazon.

Introdução

As Áreas de Preservação Permanente (APP) foram criadas para proteger o ambiente natural e restringir qualquer alteração de uso do solo, sendo proibida qualquer atividade humana. Por lei devem estar cobertas por vegetação nativa, tendo como ação ambiental de preservar os recursos hídricos (Balbinot et al., 2008).

Tratando-se de cidade localizada na região amazônica onde trafegabilidade é realizada majoritariamente por hidrovias, as cidades foram povoadas e construídas nas proximidades das beiras e barrancos dos rios. Assim esses processos de ocupações foram desordenados e acompanhados de atividades produtivas que desvalorizaram os maciços florestais, principalmente as chamadas matas ciliares (Souza et al., 2012).

Nesta parte da Amazônia o processo de ocupação por pessoas oriundas das demais regiões do país ocorreram na ausência de planejamento urbano. Em Humaitá o constante crescimento urbano e a expansão das atividades trouxeram como benefícios a geração de emprego e renda. E o Rio Madeira exerce papel central no transporte da região, destacando-se o chamado "Macro Corredor Hidroviário Manaus - Porto Velho".

As Áreas de Preservação Permanente APP foram estabelecidas pela Lei $n^{\circ} 4.771$, de
1965 (Brasil, 1965), e alterada pelas Leis $\mathrm{n}^{\circ} \mathrm{s}$ 7.803/1989, 11.284/2006 (CONAMA, 2006) e pela Medida Provisória $n^{\circ}$ 2.166-67/2001 (Brasil, 2001). Já o novo Código Florestal, Lei $n^{\circ} 12.651 / 12$. Artigo $1^{\circ}, \S 2^{\circ}$, II, as APPs constituem aquelas cobertas ou não por vegetação nativa, "com a função ambiental de preservar os recursos hídricos, a paisagem, a estabilidade geológica, a biodiversidade, o fluxo gênico de fauna e flora, proteger o solo e assegurar o bem-estar das populações humanas".

Por outro lado, o uso de ferramentas de sensoriamento remoto de fácil utilização, com rapidez e qualidade favorecem o mapeamento do uso e cobertura do solo. Propiciando o monitoramento das áreas e disponibilizar dados sobre desflorestamento das áreas de preservação permanente e outras, auxiliando na tomada de decisões. Rosa et al. (2006) enfatizam que o sensoriamento remoto é empregado para obter informações sobre o uso e cobertura do solo e monitoramento das áreas degradadas por ação antrópica.

Dessa forma o objetivo deste trabalho foi caracterizar áreas de preservação permanente (nascentes e matas riparias) de Humaitá, Amazonas, com ênfase em sua delimitação, identificação das nascentes e comparar o percentual das áreas verdes e das áreas desmatadas entre os anos 2008 e 2013, utilizando a ferramenta de geoprocessamento. 


\section{Materiais e métodos}

O estudo foi desenvolvido na cidade de Humaitá, localizada a sudoeste do Estado do Amazonas, na $5^{\text {a }}$ sub-região administrativa - Vale do Madeira, de acordo com o disposto na Constituição do Estado do Amazonas (Beltrão, 1998). A população do município é de aproximadamente 44.227 habitantes, de acordo com estimativas do Instituto Brasileiro de Geografia e Estatística (IBGE, 2014). A região sul do Amazonas ocupa uma área total de $12 \%$ do referido estado, com aproximadamente $476.297,8177 \mathrm{~km}^{2}$, abrange os municípios de Pauini, Boca do Acre, Tapauá, Lábrea, Canutama, Humaitá, Manicoré, Novo Aripuanã, Apuí e Borba.

A sede do município tem como coordenadas geográficas de centro $7^{\circ} 30^{\prime} 24^{\prime \prime}$ $\mathrm{S}$ e $63^{\circ} 01^{\prime} 40^{\prime \prime} \mathrm{W}$. A área territorial é de $33.213,3 \mathrm{~km}^{2}$, distante de Manaus $972 \mathrm{~km}$ por via fluvial e por via terrestre $679 \mathrm{~km}$, com acesso pela BR-319, a altitude média de $56 \mathrm{~m}$ acima do nível do mar. Humaitá está limitado ao norte e a leste pelo município de Manicoré; ao Sul pelo estado de Rondônia, a oeste com o município de Canutama e noroeste com Tapauá. No município de Humaitá encontram-se três áreas de nascentes e matas riparias que cortam a cidade.

Foi realizado o levantamento em campo com a utilização de um receptor de navegação GARMIN MAP 62 St com precisão de três metros. Após o trabalho de campo, no laboratório de geoprocessamento foi realizada a elaboração dos mapas, primeiramente utilizou-se o software TrackMacker 4.8 PRO para descarregamentos de dados do GPX e transformação em dados shape, logo após foram geradas as APPs com o auxílio do software ArcGIS versão 10.1 e finalização das cartas imagens. Após aplicar o buffer de 30 metros para gerar APPs de acordo com o Código Florestal Brasileiro, os dados foram visualizados no Google Earth para que fossem exportado as imagens dos anos 2008 e 2013 no formato JNP.

As áreas estudadas apresentaram as seguintes delimitações sendo a APP 1 com 10,87 hectares, APP 2 com 7,08 hectares e APP 3 com 11,27 hectares (Tabela 1).

Tabela 1. Extensão e dimensão das áreas de preservação permanentes urbanas de Humaitá, Amazonas.

\begin{tabular}{ccc}
\hline Área de Preservação Permanente & Extensão $(\mathrm{m})$ & Área (ha) \\
\hline Área 1 & $1.756,35$ & 10,87 \\
Área 2 & $1.092,31$ & 7,08 \\
Área 3 & $1.800,31$ & 11,27 \\
\hline TOTAL & $4.648,97$ & 29,23 \\
\hline
\end{tabular}




\section{Resultados e discussão}

O processamento dos dados definiu as áreas de preservação permanente ao longo dos cursos d'água, as APPs totalizam uma área de 29,23 hectares na zona urbana de Humaitá (Figura 1). Em relação a áreas com cobertura vegetal, verificou-se que aproximadamente 21,48 hectares apresentaram vegetação arbórea nativa e exótica e 7,77 hectares de áreas desflorestadas. De acordo com a resolução do CONAMA 303/2002 (Brasil, 2002) que define a área mínima de preservação permanente para os cursos d'água com menos de dez metros de largura a área de APP deve ser no mínimo trinta metros de largura e para as nascentes, independentes de seu tamanho cinquenta metros.

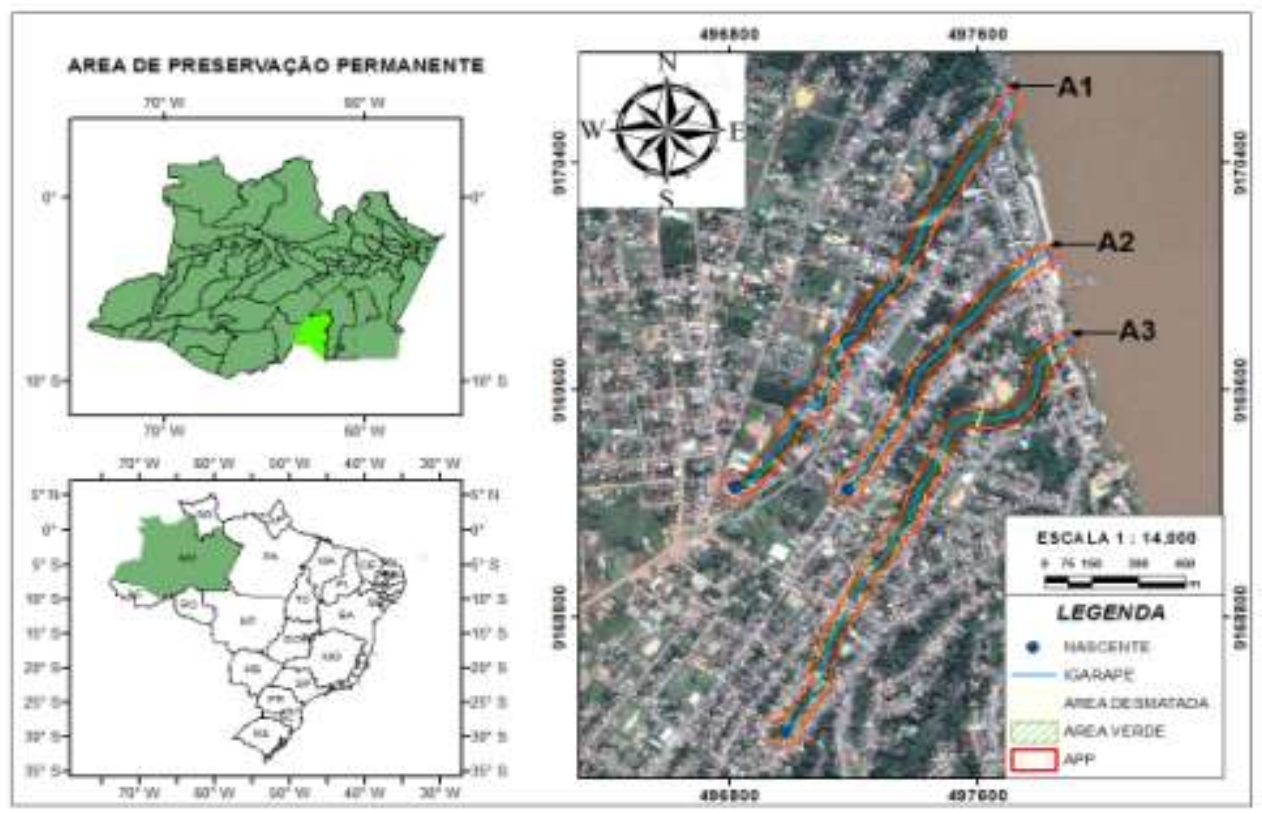

Figura 1. Mapa de localização das APPs da zona urbana do município de Humaitá, AM, em 2013.

Verificou-se que as nascentes e matas ripárias em estudo apresentaram elevado grau de ocupação desordenado em área urbana, visto que, estão inseridas na região central da cidade (Figura 1). A ocupação nas APPs são caracterizadas majoritariamente por residências, comércios, posto de gasolina e ruas que cortam essas áreas, além disso, recebem todo a carga de sedimentos, resíduos, efluentes, oriundo dessas edificações urbanas que invadem áreas de APPs (Figura 2). De acordo com Borges et. al., (2011) as APPs exercem às funções ambientais importantes, no fornecimento de bens e serviços fundamentais para toda população, bem como, regularização da vazão dos corpos d'água, retenção de sedimentos, conservação do solo, recarga do lençol freático, ecoturismo, biodiversidade, dentre outros. 
Com o uso das coordenadas planas das nascentes e curvas dos igarapés foi possível realizar a confecção do mapa temático de uso e ocupação do solo das APPs (Figura 2) segundo Barbosa et al., (2009) o geoprocessamento é uma ferramenta importante, pois auxilia mapeamento, cujo objetivo é caracterizar e entender a organização do espaço, como base no estabelecimento das ações e estudos futuros, que pode abranger assuntos relativos à geologia, geomorfologia, solos, cobertura vegetal, áreas desmatadas entre outros.

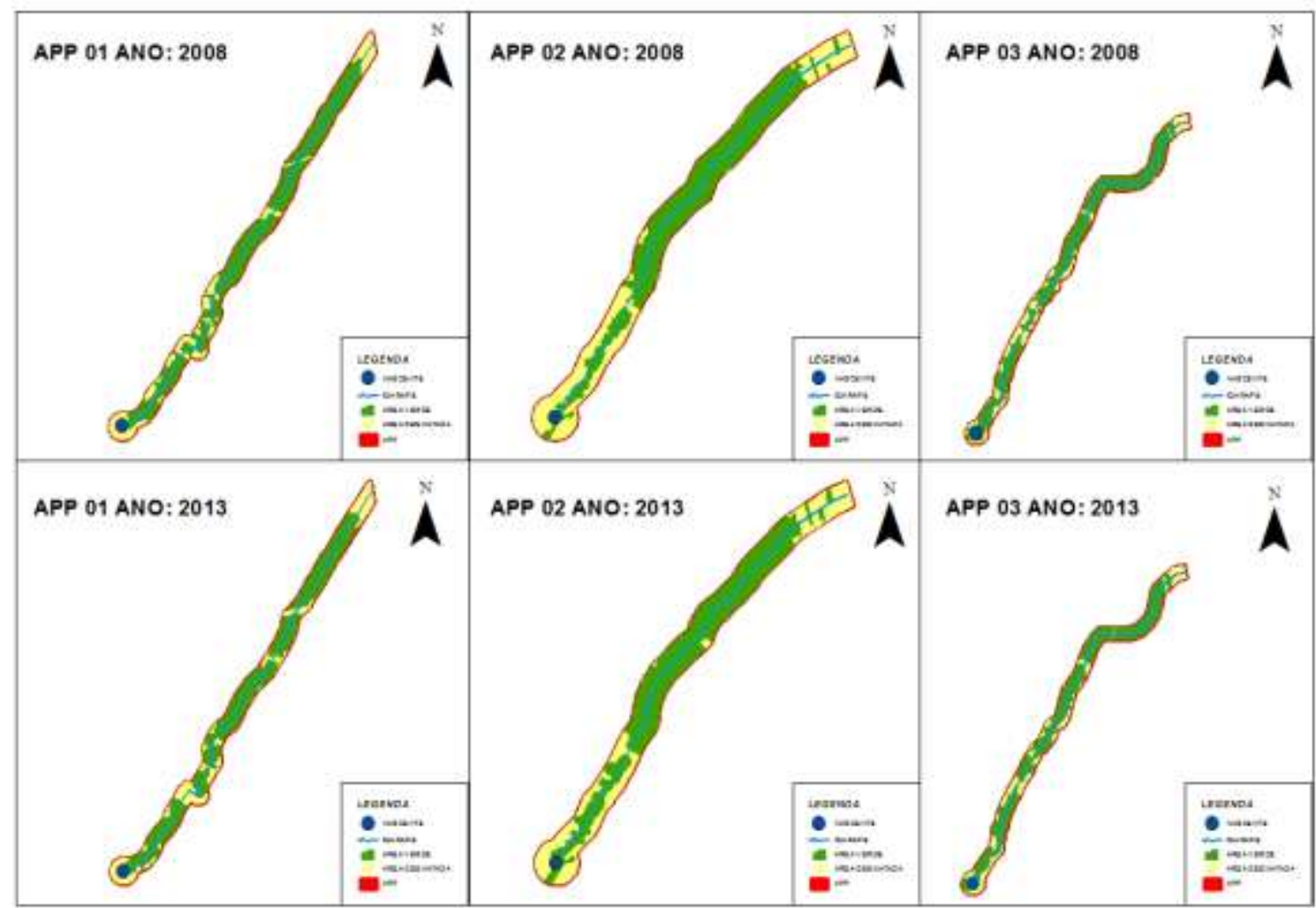

Figura 2. Mapa Temático das áreas de APPs na zona urbana do município de Humaitá, AM para os anos de 2008 e 2013.

Observou-se que em todas as três APPs estudadas tiveram em suas nascentes e nas áreas de foz junto ao Rio Madeira uma evolução do desmatamento do ano de 2008 para 2013, assim como, nos trechos médios dos igarapés coincidentes com maior urbanização da cidade (Figura 2), dessa forma comprometendo algumas funções importantes dessas áreas, como equilíbrio das margens de cursos d'água, impedindo erosão do solo, manutenção da vazão e qualidade da água, reduzindo o carreamento de sedimentos, nutrientes e produtos químicos do solo para o ambiente aquático, o que pode afetar a qualidade da água (Fisher e Sá, 2007).

Destaca-se que as áreas de APP-1 e APP-3 apresentaram um maior aumento da área desmatada e diminuição da área verde, já 
a APP-2 apresentou diminuição da área desmatada e aumento da área verde; podendo ser caracterizado pelo relevo da cidade, que contem áreas de topografia acidentada e altitude baixa chamado de grotas, ou seja, dificultando a atividade antrópica naquele terreno.

\section{Conclusões}

Houve evolução no processo de ocupação desordenada e desmatamento das áreas de APPs para os anos de 2008 e 2013 na zona urbana do município de Humaitá, AM;

As áreas de APP-1 e APP-3 apresentaram um aumento da área desmatada e diminuição da área verde, já a APP-2 apresentou diminuição da área desmatada e aumento da área verde;

A utilização de mapas permitiu analisar espacialmente o processo de redução das áreas verdes, decorrentes das alterações no uso e ocupação do solo pelo qual passou a zona urbana do município de Humaitá, AM.

\section{Referências}

BALBINOT, R. et al. O papel da floresta em ciclos hidrológicos em bacias hidrográficas. Ambiência, Guarapuava, v.4, n.1, p.131-149, 2008.

BARBOSA, Í.S. et al. Evolução da cobertura vegetal e uso agrícola do solo no município de Lagoa Seca, PB. Revista Brasileira de Engenharia Agrícola e Ambiental. Campina Grande, v.13, n.5, p.615-622, 2009.
BELTRÃO, Otto. Realidade da Amazônia Brasileira. Vol. Amazonas. Fundação Biblioteca Nacional: Ministério da Cultura, 1998.

BORGES, L.A.C. et al. Áreas de preservação permanente na legislação ambiental brasileira. Ciência Rural, Santa Maria, v.41, n. 7, p.1202-1210, 2011.

BRASIL. Lei 4.771, de 15 de setembro de 1965. Instituiu o código florestal brasileiro. Brasília, DF, 1965. Disponível em: < ht t p :/ / www. pl a na 1 t o. g ov. b r/ ccivi 1_0 $3 / \mathrm{L}$ eis/ L 4771 . h t m>. Acesso em: 24/12/2014.

BRASIL. Medida Provisória 2.166-67, de 24 de agosto de 2001. Altera os arts. 1, 4, 14, 16 e 44, e acresce dispositivos

à Lei n. 4.771 de 1965: código florestal.

Brasília, DF, 2001. Disponível em: <http://www.planalto.gov.br/ccivil_o 3 /mpv/ 2166-67.htm>. Acesso em: 23/12/2014.

BRASIL. Conselho Nacional de Meio Ambiente. Resolução no 303, de 20 de março de 2002. Dispõe sobre parâmetros, definições e limites de Áreas de Preservação Permanente. Disponível em: <www.mma.gov.br/port/conama/res/res02/res 30302.html >. Acesso em: 23/12/2014.

BRASIL. Lei $n^{\circ} 4.771$, de 15 de setembro de 1965. Código Florestal Brasileiro. In: Senado Federal. Legislação Republicana Brasileira. Disponível em: <http://www.planalto.gov.br/ccivil_03/LEIS/ L4771. htm>. Acesso em: 18/09/2014.

BRASIL. Medida Provisória 2.166-67, de 24 de agosto de 2001. Altera os arts. $1^{\circ}, 4^{\circ}, 14$, 16 e 44, e acresce dispositivos à Lei n. 4.771 de 1965: código florestal. Brasília, DF, 2001. Disponível em: <http://www.planalto.gov.br/ccivil_03/mpv/2 166-67.htm>. Acesso em: 20 jan. 2014. 
CONAMA. Conselho Nacional de Meio

Ambiente. Resolução n. 369, de 28 de março de 2006. Dispõe sobre os casos excepcionais, de utilidade pública, interesse social ou baixo impacto ambiental, que possibilitam a intervenção ou supressão de vegetação em Área de Preservação Permanente - APP. Brasília, DF, 2006. Disponível em: <http://www.mma.gov.br/port/conama/leg iabre.cfm?codlegi=489>. Acesso em: 20 jul. 2014.

FISHER, L.R.C.; SÁ, J.D.M. Estatuto da cidade e a resolução Conama n. 369/2006. In: Seminário sobre o tratamento de áreas de preservação permanente em meio urbano e restrições ambientais o parcelamento do solo, 2007, São Paulo, SP. Anais... São Paulo:

FAUUSP, 2007. CD-ROM.

ROSA, R. et al. Uso do Solo e Cobertura Vegetal na Área de Influência do AHE Capim Branco. Sociedade \& Natureza, Uberlândia, v.18, n.34, p.133-150, 2006.

SOUZA, S. R. et al. Caracterização do conflito de uso e ocupação do solo nas áreas de preservação permanente do rio Apeú, Nordeste do Pará. Floresta, Curitiba, PR, v. 42, n. 4, p.701-710, 2012. 